\title{
Integranular corrosion susceptibility analysis in austeno-ferritic (duplex) stainless steels
}

\author{
Francesco Iacoviello*, Vittorio Di Cocco, Laura D’Agostino \\ Università di Cassino e del Lazio Meridionale, DICeM, via G. Di Biasio 43, 03043 Cassino (FR), Italy
}

\begin{abstract}
Austenitic-ferritic stainless steels combine the favorable properties of ferrite and austenite, showing both high mechanical properties and very good corrosion resistance. These steels are characterized by the precipitation of many secondary phases, carbides and nitrides for tempering temperatures between 200 and $1050^{\circ} \mathrm{C}$. This phenomenon implies a high susceptibility to localized corrosion, however better than austenitic and ferritic grades. In this work, the susceptibility to intergranular corrosion in of two duplex stainless steel characterized by analogous ferrite/austenite volume fraction was investigated. A "standard" duplex stainless steel SAF 2205 and a "super" duplex stainless steel SAF 2507 were investigated by means of potentiostatic reactivations tests. In addition, chronoamperometric tests and light optical microscope observations of the specimens surfaces were performed in order to analyze the evolution of the corrosion morphologies.
\end{abstract}

Copyright $(2017$ The Authors. Published by Elsevier B.V. This is an open access article under the CC BY-NC-ND license (http://creativecommons.org/licenses/by-nc-nd/4.0/).

Peer-review under responsibility of the Scientific Committee of IGF Ex-Co.

Keywords: Duplex Stainless Steels; Intergranular corrosion; DL-EPR test.

\section{Introduction}

Because of their austenitic-ferritic microstructure, duplex stainless steels offer a good combination of mechanical properties and corrosion resistance compared to standard austenitic grades, Gunn (1997). They are widely used in chemical, petrochemical, fertilizer, nuclear and cellulose industries.

\footnotetext{
* Corresponding author. Tel.: +39.07762993681.
}

E-mail address: iacoviello@unicas.it 
These steels solidify liquid + ferritic field and it is during cooling of the solid that a partial ferrite transformation into austenite takes place. The amount of austenite and ferrite phases depends on chemical composition and cooling rate, Brandi (1997). The best combination of mechanical properties and corrosion resistance is obtained with a $\alpha / \gamma$ volume ratio near to 1 . Duplex stainless steels are characterized by many microstructure modifications (Fig. 1).

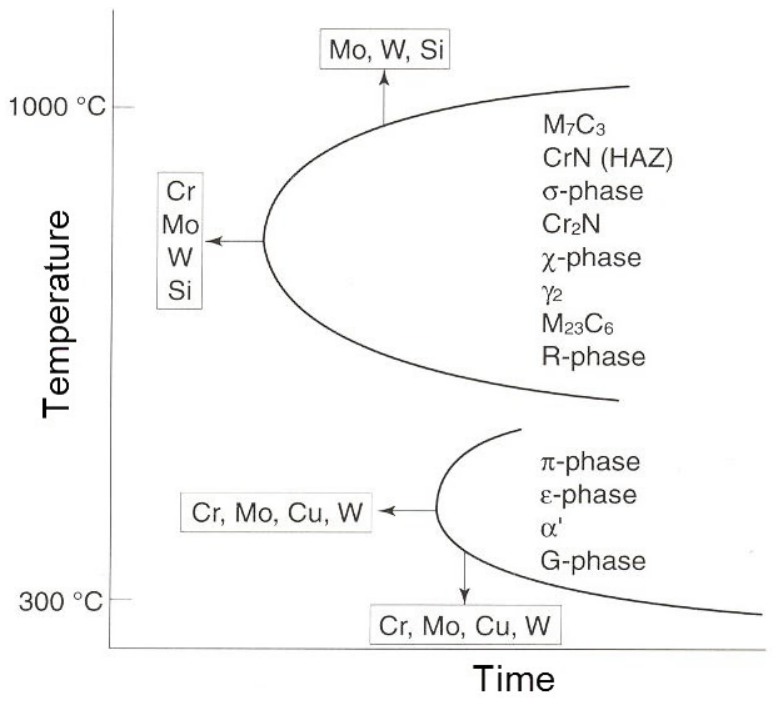

Fig. 1. Austenitic-ferritic stainless steels: T.T.T (Transformation-Time-Temperature) diagram.

Above $1050^{\circ} \mathrm{C}$, austenite transforms into ferrite. This ferritisation process implies a modification both in volume fraction and in partition coefficients, with an increasing of interstitial elements content (e.g. hydrogen and nitrogen) in ferrite grains. Below $1050^{\circ} \mathrm{C}$, duplex stainless steels show two different critical temperature ranges.

In the $600-1050^{\circ} \mathrm{C}$ range many carbides, nitrides, intermetallic and secondary phases could precipitate. Carbides $\mathrm{M}_{7} \mathrm{C}_{3}$ (between 950 and $1050^{\circ} \mathrm{C}$ ), carbides $\mathrm{M}_{23} \mathrm{C}_{6}$ (between 600 and $950^{\circ} \mathrm{C}$ ), nitrides $\left(\pi, \mathrm{CrN}, \mathrm{Cr}_{2} \mathrm{~N}\right.$ ), intermetallic phases $(\sigma, \chi, \mathrm{R})$ and secondary austenite $\gamma_{2}$ precipitate in ferrite grains or in $\alpha / \gamma$ or $\alpha / \alpha$ grain boundaries, Josefsson (1991). This precipitation implies a strong mechanical properties modification and an evident fatigue crack propagation resistance decreasing, Iacoviello (1997) and Iacoviello (1999).

In the temperature range between about 350 and $600{ }^{\circ} \mathrm{C}$, the spinodal decomposition of ferrite grains and a fcc $\mathrm{G}$ phase precipitation at $\alpha / \gamma$ grain boundaries take place, Iacoviello (2005). G phase particles are characterized by a composition that varies according to the steel and to the ageing conditions, with the overall concentration of $\mathrm{Ni}+\mathrm{Si}+\mathrm{Mo}+\mathrm{Mn}+\mathrm{Al}$ that increase from 40 to $60 \%$ between 1000 and $30000 \mathrm{~h}$ at $350^{\circ} \mathrm{C}[10]$.

In this work, two duplex stainless steels (a $22 \mathrm{Cr} 5 \mathrm{Ni}$ and a $25 \mathrm{Cr} 7 \mathrm{Ni}$ ) with analogous ferrite and austenite volume fractions were considered and their susceptibility to the intergranular corrosion was investigated after sensitization at $800^{\circ} \mathrm{C}$ by means of DL-EPR tests, chronoamperometric tests and light optical microscope specimens surface observations.

\section{Investigated steels and experimental procedures}

The investigated duplex stainless steels chemical composition and tensile properties are shown in Tabs. 1 and 2.

Table $1.22 \mathrm{Cr} 5 \mathrm{Ni}(\%$ ferrite $=\%$ austenite $=50)$ chemical composition and tensile properties.

\begin{tabular}{ccccccccc}
\hline $\mathrm{C}$ & $\mathrm{Si}$ & $\mathrm{Mn}$ & $\mathrm{P}$ & $\mathrm{S}$ & $\mathrm{Cr}$ & $\mathrm{Ni}$ & $\mathrm{Mo}$ & $\mathrm{N}$ \\
0.019 & 0.39 & 1.51 & 0.022 & 0.002 & 22.45 & 5.50 & 3.12 & 0.169 \\
\hline YS [MPa] & UTS [MPa] & $\mathrm{A} \%$ & 35 & & & \\
565 & 827 & & 35 &
\end{tabular}


Table 2. $25 \mathrm{Cr} 7 \mathrm{Ni}(\%$ ferrite $=\%$ austenite $=50)$ chemical composition and tensile properties.

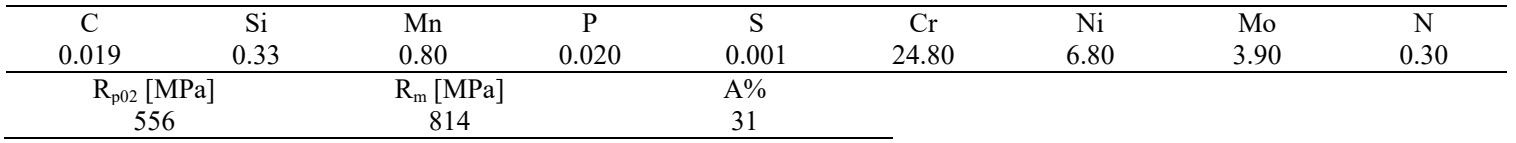

It is worth to note that both investigated stainless steels are characterized by the same $\mathrm{C}$ content and by analogous ferrite and austenite volume fractions. Both stainless steels were sensitized at $800^{\circ} \mathrm{C}$ for $1,3,10$ and 100 hours (the most critical temperature, considering the mechanical properties evolution). The microstructure evolution due to these sensitization treatments is shown in Figs. 2 and 3 (Scanning Electron Microscope, SEM, observations).

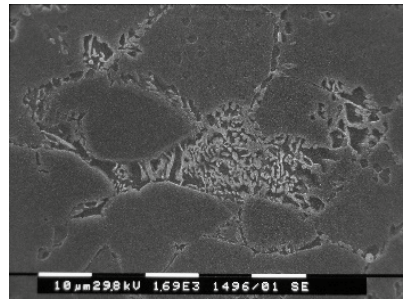

$800^{\circ} \mathrm{C}-1 \mathrm{~h}$

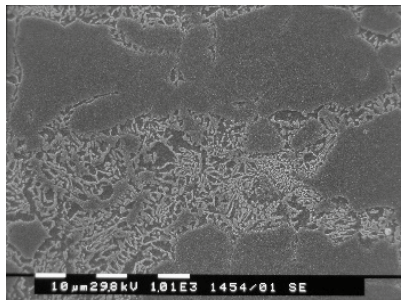

$800^{\circ} \mathrm{C}-3 \mathrm{~h}$

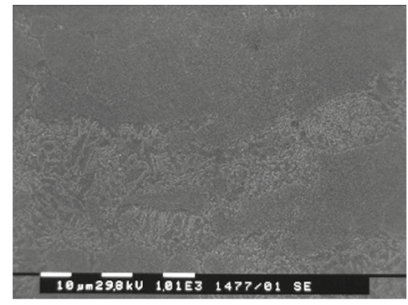

$800^{\circ} \mathrm{C}-10 \mathrm{~h}$

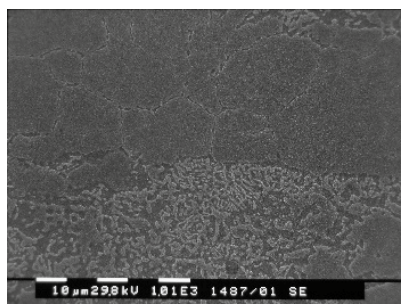

$800^{\circ} \mathrm{C}-100 \mathrm{~h}$

Fig. 2: Duplex stainless steel $22 \mathrm{Cr} 5 \mathrm{Ni}$ : microstructure evolution at $800^{\circ} \mathrm{C}$.

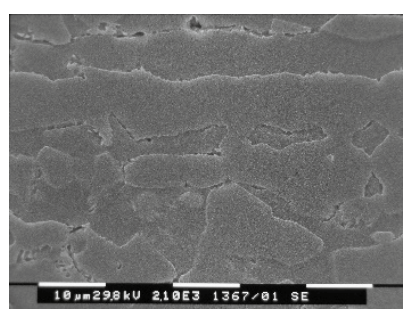

$800^{\circ} \mathrm{C}-1 \mathrm{~h}$

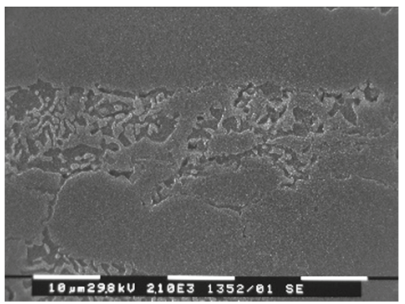

$800^{\circ} \mathrm{C}-3 \mathrm{~h}$

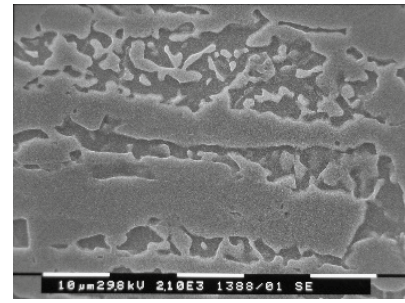

$800^{\circ} \mathrm{C}-10 \mathrm{~h}$

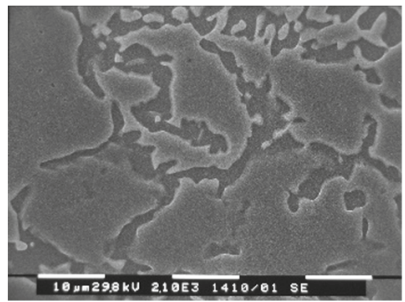

$800^{\circ} \mathrm{C}-100 \mathrm{~h}$

Fig. 3: Superduplex stainless steel $25 \mathrm{Cr} 7 \mathrm{Ni}$ : microstructure evolution at $800^{\circ} \mathrm{C}$.

Duplex 2205 steel is characterized by the ferrite decomposition according to the eutectoid reaction $\delta \rightarrow \sigma+\gamma$, with the precipitation of $\sigma$ phase and secondary austenite already after 1 hour at $800^{\circ} \mathrm{C}$. Also carbides precipate but, after three hours at $800^{\circ} \mathrm{C}$ they are no more evident.

After 1 hour at $800^{\circ} \mathrm{C}$, superduplex 2507 shows only the carbides precipitation (mainly at $\alpha / \gamma$, but also at $\alpha / \alpha$ grain boundaries. Longer treatments at $800^{\circ} \mathrm{C}$ shows the ferrite grains decomposition according to the to the eutectoid reaction $\delta \rightarrow \sigma+\gamma$. After three hours at $800^{\circ} \mathrm{C}$, carbides at grains boundaires are still evident, but, after ten hours at $800^{\circ} \mathrm{C}$, carbides are no more evident.

Sensitization susceptibility was investigated by means of Double Loop Electrochemical Reactivation Test (DL-EPR test), Cihal (2001). It allows to perform measurements both in laboratory conditions and in situ, and, compared to the conventional corrosion test, EPR test is quicker, more sensitive and more accurate, especially investigating low sensitized conditions. Two different EPR procedures are usually followed: single loop test (SL-EPR) and double loop test (EPR-DL). In SL-EPR tests, a potential scan from the passive range to open circuit potential is followed. Instead, in DL-EPR tests a cyclic polarization curve is applied on a metallographically prepared specimen: the polarization curve consists in a forward scan followed by a reverse scan starting at the active open circuit potential (Fig. 4). This procedure is standardized for AISI 304 and 304L, ASTM G108 (2015). Considering the DL-EPR test, the sensitization degree of a stainless steel can be evaluated considering the ratio between the area of the reactivation stage and the area of the activation stage (e.g, $\left.\mathrm{Q}_{\mathrm{R}} / \mathrm{Q}_{\mathrm{P}}\right)$.

DL-EPR tests were performed according to the following procedure: 
- $\quad$ after being sensitized, specimens with a surface of $1 \mathrm{~cm}^{2}$ were metallographically prepared;

- a $0.5 \mathrm{M} \mathrm{H}_{2} \mathrm{SO}_{4}+0.01 \mathrm{KSCN}$ aqueous solution was considered, Iacoviello (1997). Bubbling argon was used to stir the solution and ensure an oxygen-free electrolyte;

- Before polarizing the samples, the open circuit potential was measured for $2 \mathrm{~min}$.

- Investigated potential range: $-500 \mathrm{mV} / \mathrm{SCE}$ - +200 $\mathrm{mV} / \mathrm{SCE}$ (Sweep rate: $50 \mathrm{mV} / \mathrm{min}$ ).

In order to control results repeability, DL-EPR tests were repeated five times (confirming the very high repeability of the results obtained with DL-EPR testing procedure).

Corresponding to some electrochemical conditions (defined on the basis of the results of the DL-EPR tests) some chronoamperometric tests were performed and the specimens surfaces were observed by means of a SEM.

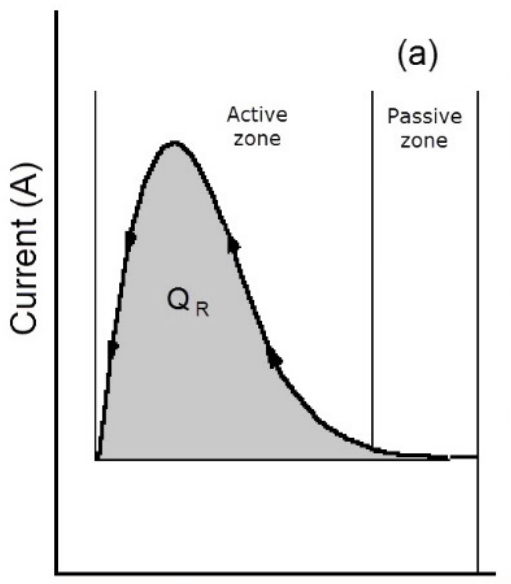

Potential (V)

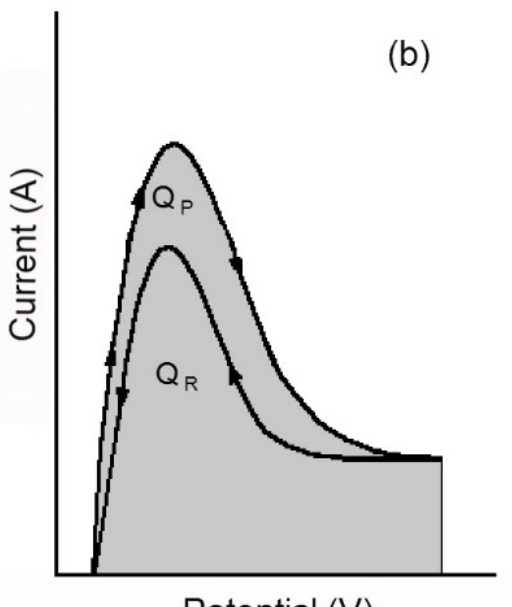

Potential (V)

Fig. 4. (a) SL-EPR test; (b) DL-EPR test.

\section{Experimental results and discussion}

Both 2205 and 2507 activation curves (Fig. 5 and 6 left) are characterized by a double peak due to their duplex microstructure, with the maximum current density that increases with the sensitization duration. Both investigated steels show very low reactivation curves: as a consequence, in both cases it is necessary a second diagram with a different current density axis (Fig. 5 an Fig. 6, on the right).
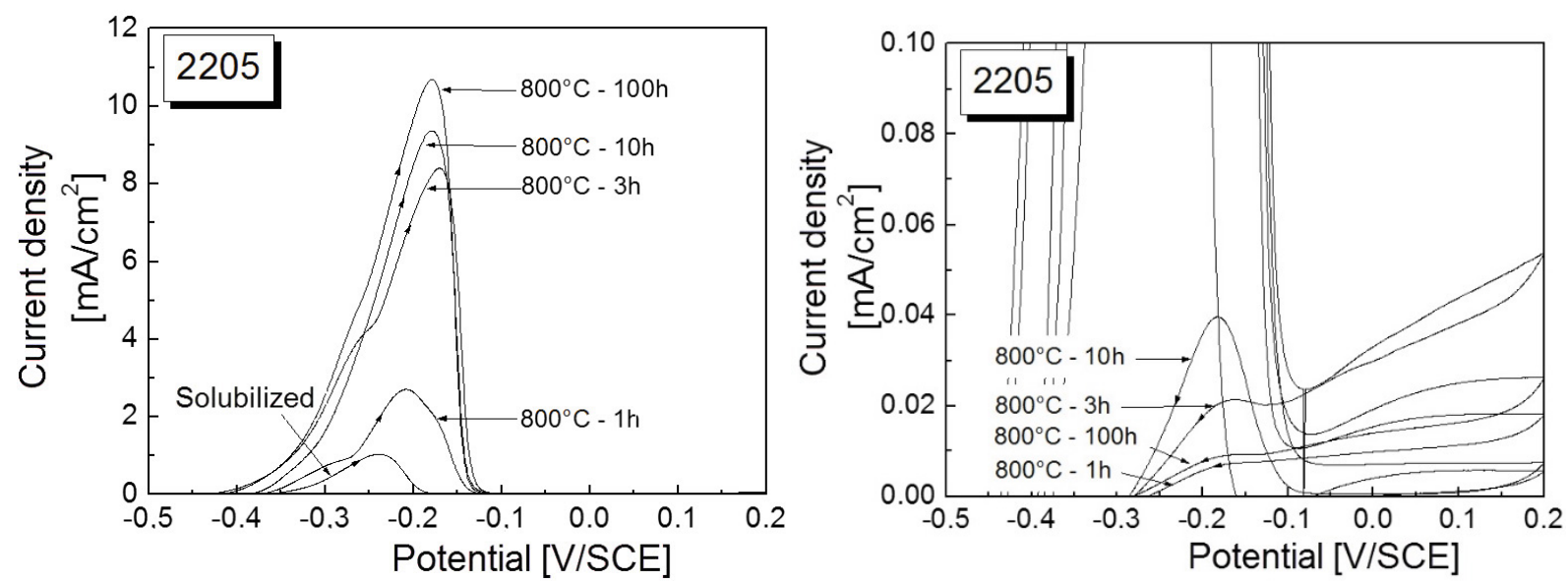

Fig. 5: Duplex 2205. DL-EPR tests results: activation curves (left); reactivation curves (right). 

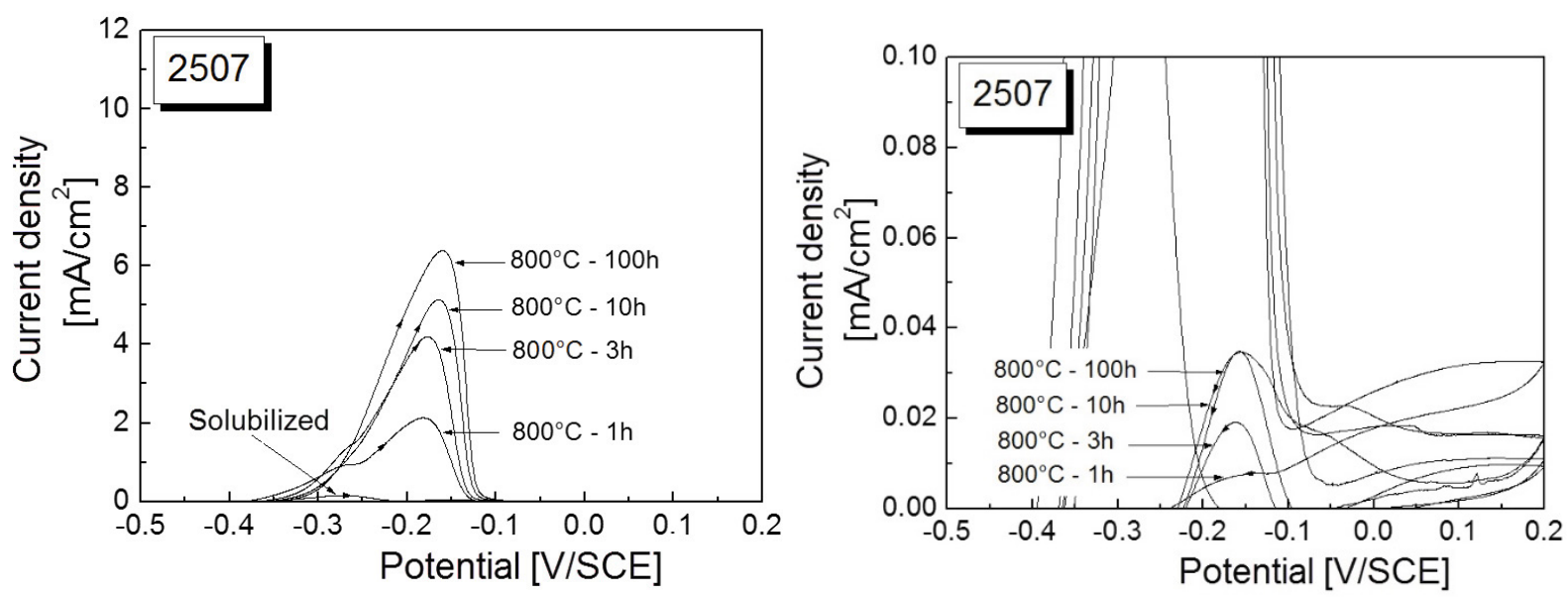

Fig. 6: Duplex 2507. DL-EPR tests results: activation curves (left); reactivation curves (right).

In 2205, the current density peaks of the reactivation curves increase with the sensitization process duration up to 10 hours. For longer sensitization process (100 hours), the current density peak decrease. This can be connected to the microstructure evolution and with the carbides dissolution for longer sensitization processes.

A careful observation of the activation curves of the 2507 stainless steel show some additional activation peaks that are more evident for longer sensitization processes (due to the long list of secondary phases and nitrides that precipitate at high temperature, Fig. 1). The reactivation curves are characterized by an increase of the reactivation peak up to 3 hours, with longer sensitization duration $(100 \mathrm{~h})$ that show a peak that is analogous to the peak obtained after 3 hours.

Analyzing the evolution of the sensitization peaks with the sensitization time, the superduplex 2507 steel is characterized by higher values of the $\mathrm{Q}_{\mathrm{R}} / \mathrm{Q}_{\mathrm{P}}$ ratio, especially for longer sensitization times. This is probably due to the chemical composition influence on the TTT diagram and to consequent shorter incubation times for the precipitation of carbides, nitrides and secondary phases.

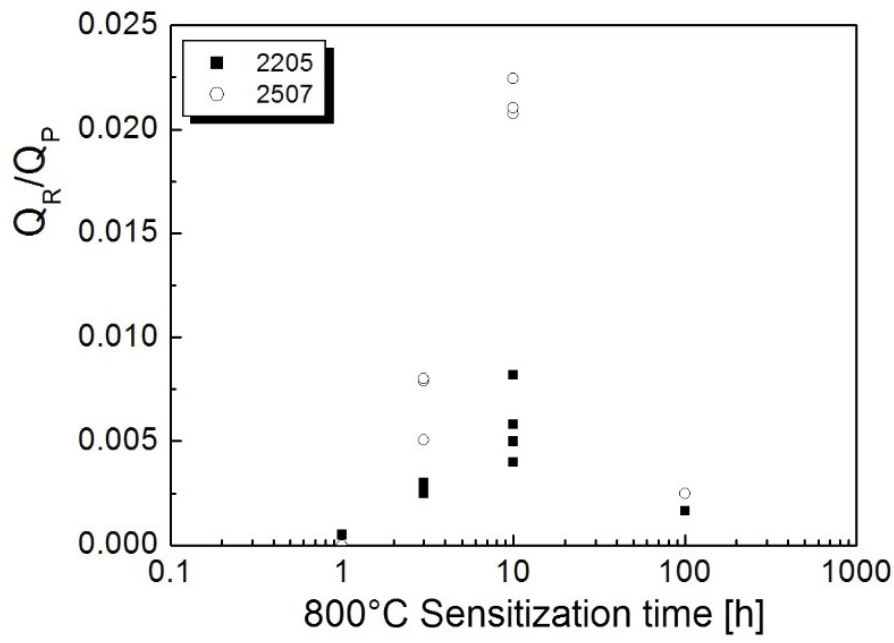

Fig. 7. Sensitizing index $Q_{R} / Q_{P}$ evolution with the $800^{\circ} \mathrm{C}$ sensitizing treatment for the two investigated stainless steels.

The results of chronoamperometric tests performed at $-190 \mathrm{mV} / \mathrm{SCE}$ are shown in Fig. 8 and 9, respectively for the 2205 and for the 2507 stainless steel. 


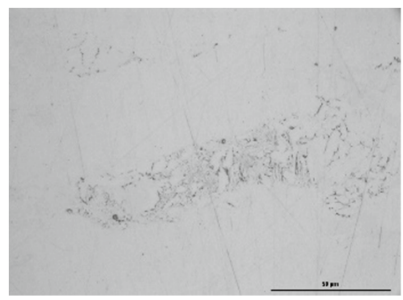

$800^{\circ} \mathrm{C}-1 \mathrm{~h}$

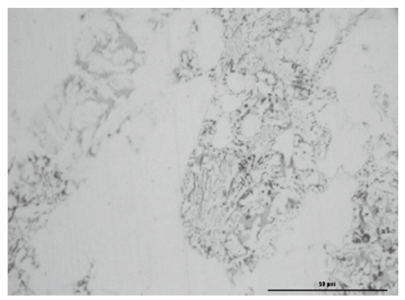

$800^{\circ} \mathrm{C}-3 \mathrm{~h}$

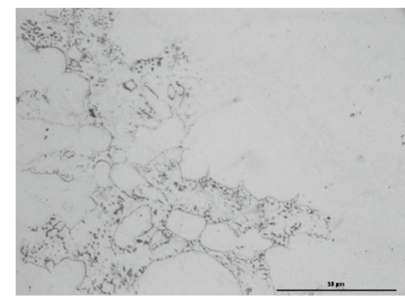

$800^{\circ} \mathrm{C}-10 \mathrm{~h}$

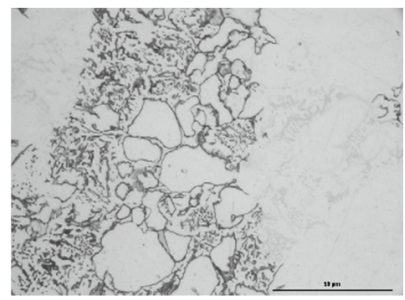

$800^{\circ} \mathrm{C}-100 \mathrm{~h}$

Fig. 8: Duplex stainless steel $22 \mathrm{Cr} 5 \mathrm{Ni}$ : corrosion morphology evolution after a chronoamperometric test at $-190 \mathrm{mV} / \mathrm{SCE}$ for different $800^{\circ} \mathrm{C}$ sensitization times.

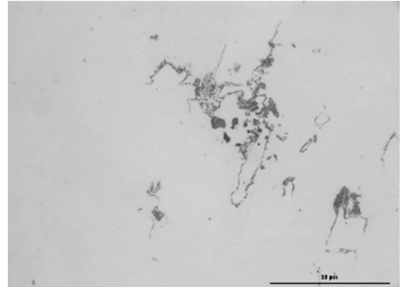

$800^{\circ} \mathrm{C}-1 \mathrm{~h}$

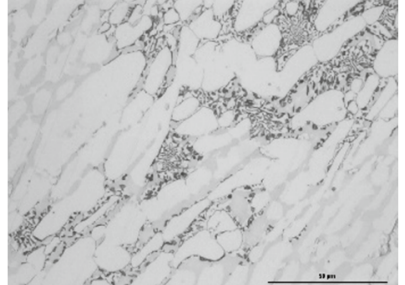

$800^{\circ} \mathrm{C}-3 \mathrm{~h}$

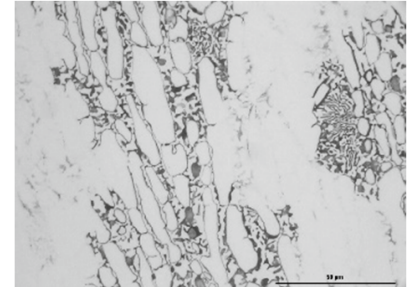

$800^{\circ} \mathrm{C}-10 \mathrm{~h}$

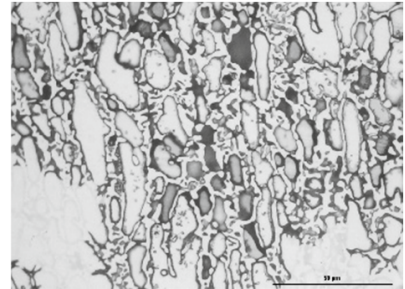

$800^{\circ} \mathrm{C}-100 \mathrm{~h}$

Fig. 9: Superduplex stainless steel $25 \mathrm{Cr} 7 \mathrm{Ni}$ : corrosion morphology evolution after a chronoamperometric test at $-190 \mathrm{mV} / \mathrm{SCE}$ for different $800^{\circ} \mathrm{C}$ sensitization times.

Both investigated stainless steels are characterized by the superposition of two localised corrosion phenomena, at least:

- Intergranular corrosion, that is already evident after an $800^{\circ} \mathrm{C}$ sensitization process of one hour;

- a selective attack of the ferritic grains that, at $800^{\circ} \mathrm{C}$, decompose according to the reaction $\delta \rightarrow \sigma+\gamma$. This corrosion attack morphology is more and more evident with the sensitization time.

The different precipitation kinetics, due to the different chemical compositions, are the responsible of the different susceptibility to the localised corrosion (both intergranular and selective attacks). Although the investigated steels are characterized by the same $\mathrm{C}$ content, the superduplex 2507 stainless steels seems to be more susceptible to localized corrosion processes if compared to the "standard". 2207 steel. It is evident that, considering the duplex stainless steels and the peculiar chemical composition influence on TTT curves, the sensitization index $\mathrm{Q}_{\mathrm{R}} / \mathrm{Q}_{\mathrm{P}}$ can be considered as characterizing the intergranular corrosion process only as a first approximation, being influenced by the other localized corrosion mechanisms that can occur at the same potentials that characterize the intergranular phenomenon.

\section{Conclusion}

In this work, the sensitization susceptibility of two austeno-ferritic(duplex) stainless steels (a "standard" SAF 2205 and a "super" duplex SAF 2507)) was investigated by means of Double Loop - Electrochemical reactivation tests and Chronoamperometric tests followed by a light optical microscope observations of the specimens surfaces. According to the obtained results, it is possible to summarize the following conclusions:

- being the carbides and ferrite grains decomposition influenced by the steel chemical composition (with incubation times that decrease with the increase of the alloying elements), also the localized corrosion processes in duplex stainless steels are influenced by the chemical composition: superduplex stainless steel 2507 seems to be more susceptible to localized corrosion attack (both intergranular and selective corrosion)than the "standard" 2205 stainless steel. 
- for the investigated sensitization temperature $\left(800^{\circ} \mathrm{C}\right)$ and all the sensitizations times, the intergranular corrosion attack occurs at the same time of the selective attack of the ferritic grains, being this superposition more and more evident with the increase of the sensitization time;

- DL-EPR test does not seem to be the best procedure to characterize the intergranular corrosion susceptibility in a steel when a second localized corrosion attack (e.g., ferritic grains selective attack) occurs at the same time.

\section{References}

Brandi. S.D., Lippold. J.C., 1997. Considerações sobre a metalurgia da soldagem de aços inoxidáveis duplex e superduplex. Metallurgia \& Materiais. 141-146.

Charles, J., 2016. Duplex Stainless steels - a Review after DSS '07 held in Grado. Steel Research International. 79, 455-465.

Cihal, V., Stefec, R., 2001. On the development of the electrochemical potentiokinetic method. Electrochimica Acta, 46(24-25), 3867-3877.

Gunn, R., 1997. Duplex Stainless Steels: Microstructure. Properties and Applications. Woodhead Publishing.

Iacoviello. F., Habashi, M., Cavallini, M., 1997. Hydrogen embrittlement in the duplex stainless steel Z2CND2205 hydrogen-charged at $200^{\circ} \mathrm{C}$. Mater. Science and Engineering A. A224, 116-124.

Iacoviello. F., Boniardi, M., La Vecchia, G.M., 1999. Fatigue crack propagation in austeno-ferritic stainless steel 22 Cr 5 Ni. Int. J. of Fatigue. 21, 957-963.

Iacoviello, F., Casari, F., Gialanella, S., 2005. Effect of " $475^{\circ} \mathrm{C}$ embrittlement" on duplex stainless steels localised corrosion resistance. Corrosion Science. 47, 909-922.

Josefsson, B., Nilsson, J.O., Wilson, A., 1991. Phase transformations in duplex steels and the relation between continuous cooling and isothermal heat treatment. Duplex Stainless Steel '91, Beaune, France. 1, 67-78. 